\title{
Unique AGG Interruption in the CGG Repeats of the FMR1 Gene Exclusively Found in Asians Linked to a Specific SNP Haplotype
}

\author{
Pornprot Limprasert, ${ }^{1}$ Janpen Thanakitgosate, ${ }^{2}$ \\ Kanoot Jaruthamsophon, ${ }^{1}$ and Thanya Sripo ${ }^{1}$ \\ ${ }^{1}$ Department of Pathology, Faculty of Medicine, Prince of Songkla University, Songkhla 90110, Thailand \\ ${ }^{2}$ Department of Pathology, Faculty of Medicine, Ramathibodi Hospital, Mahidol University, Bangkok 10400, Thailand
}

Correspondence should be addressed to Pornprot Limprasert; lpornpro@yahoo.com

Received 27 November 2015; Accepted 31 January 2016

Academic Editor: Norman A. Doggett

Copyright ( $) 2016$ Pornprot Limprasert et al. This is an open access article distributed under the Creative Commons Attribution License, which permits unrestricted use, distribution, and reproduction in any medium, provided the original work is properly cited.

\begin{abstract}
Fragile X syndrome (FXS) is the most common inherited intellectual disability. It is caused by the occurrence of more than 200 pure CGG repeats in the FMR1 gene. Normal individuals have 6-54 CGG repeats with two or more stabilizing AGG interruptions occurring once every 9- or 10-CGG-repeat blocks in various populations. However, the unique (CGG)6AGG pattern, designated as $6 \mathrm{~A}$, has been exclusively reported in Asians. To examine the genetic background of AGG interruptions in the CGG repeats of the FMR1 gene, we studied 8 SNPs near the CGG repeats in 176 unrelated Thai males with 19-56 CGG repeats. Of these 176 samples, we identified AGG interruption patterns from 95 samples using direct DNA sequencing. We found that the common CGG repeat groups (29, 30, and 36) were associated with 3 common haplotypes, GCGGATAA (Hap A), TTCATCGC (Hap C), and GCCGTTAA (Hap B), respectively. The configurations of 9A9A9, 10A9A9, and 9A9A $6 \bar{A} 9$ were commonly found in chromosomes with 29,30 , and 36 CGG repeats, respectively. Almost all chromosomes with Hap B (22/23) carried at least one 6A pattern, suggesting that the $6 \mathrm{~A}$ pattern is linked to Hap B and may have originally occurred in the ancestors of Asian populations.
\end{abstract}

\section{Introduction}

The cause of fragile X syndrome (FXS) is the expansion of CGG repeats in the $5^{\prime} \mathrm{UTR}$ of the FMR1 gene and subsequent hypermethylation at the $\mathrm{CpG}$ island in the promoter region of this gene, leading to transcriptional silence of the mRNA and absence of FMRP translation $[1,2]$. Affected full mutation individuals have $>200$ pure CGG repeats. Premutation carriers have 55-200 CGG repeats with one AAG interruption or absent AGG interruption resulting in increasing length of pure CGG repeats at the $3^{\prime}$ end of the CGG repeat tracts. Normal individuals have 6-54 CGG repeats with two or more stabilizing AGG interruptions occurring once every 9 or 10 CGG repeat blocks $[3,4]$. The common patterns are (CGG)9AGG and (CGG)10AGG, found in various populations. However, the (CGG)6AGG pattern (designated as 6A) has been reported exclusively in Asian populations [5-11], leading to the possibility that this $6 \mathrm{~A}$ pattern may have originated in Asia.

To explore the evolution of the $6 \mathrm{~A}$ pattern, we studied 176 unrelated Thai males with 19-56 CGG repeats using 8 SNPs near the CGG repeats of the FMR1 gene. Of these 176 samples, we identified AGG interruption patterns from 95 samples with different CGG repeats using direct DNA sequencing. We found a specific SNP haplotype linked to the $6 \mathrm{~A}$ pattern, and we also found something new that the SNP haplotypes showed strong associations between the common CGG repeat groups (29, 30, and 36) and AGG interruption patterns, suggesting different evolutionary lineages in the common CGG repeats of the FMR1 gene. 


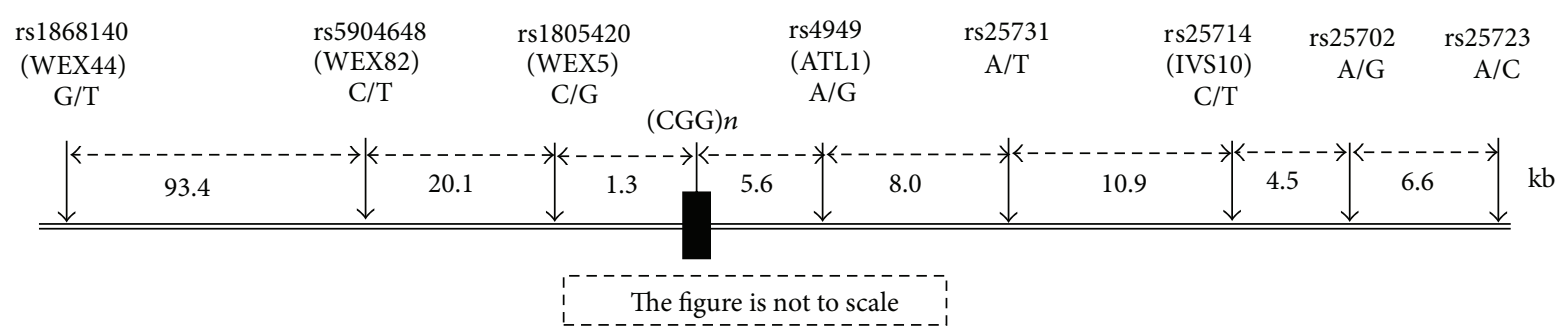

(a)

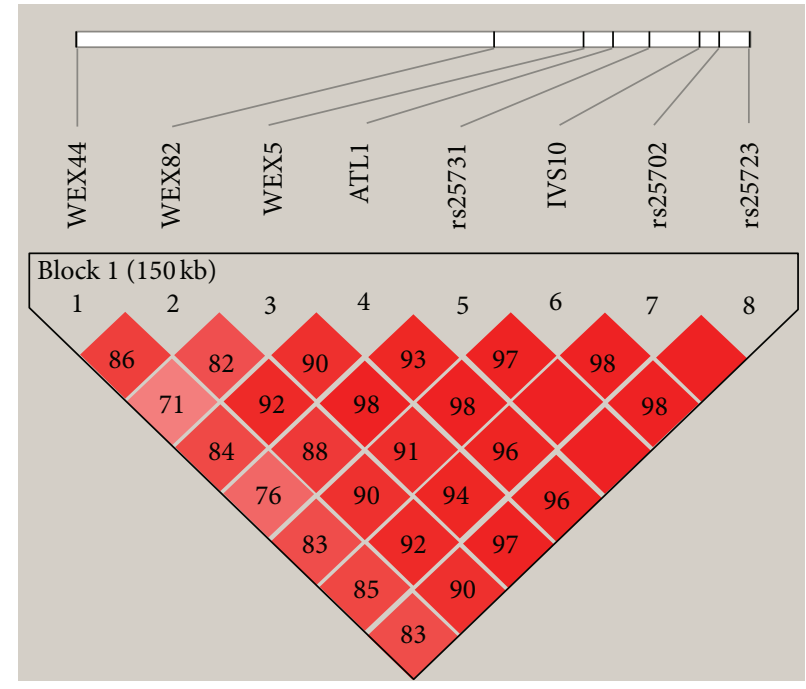

(b)

Figure 1: (a) The locations of the 8 SNPs. SNP-alleles of each locus are indicated under the SNPs. The distance between each SNP in Kb is shown below. The figure is not to scale. (b) Linkage disequilibrium $\left(D^{\prime}\right)$ plot of the 8 SNPs within $150 \mathrm{~kb}$ of the CGG-FMR1 gene. All SNPs pairs have high $D^{\prime}$ values, more than 80 or close to 80 .

\section{Materials and Methods}

2.1. DNA Samples. DNA was extracted from whole blood using the standard phenol/chloroform method. The PCR for the CGG-FMR1 gene and methylation specific PCR were used with minor modification as previous reports $[15,16]$. We selected 176 unrelated Thai males in this study, ranging from 19 to 56 CGG repeats. At this time the Thai population is known to have three common alleles, 29, 30, and 36 CGG repeats [15]. In the analysis, samples were divided into 6 groups corresponding to common and uncommon CGG repeats: $19-28,29,30,31-35,36$, and 37-56. The study protocol was approved by the Institutional Ethics Committee.

2.2. SNP Study. We selected 2 prior investigated SNPs, ATL1 or rs4949, IVS10 or rs25714 [17]. Six additional SNPs, WEX44 (rs1868140), WEX82 (rs5904648), WEX5 (rs1805420), rs25731, rs25702, and rs25723, were obtained from the previous reports $[12,13,18]$. The FMR1 genomic and SNP position references were according to GenBank reference sequences L29074 and NC_000023.11. These SNPs are located both proximally and distally to the CGG repeats region of the FMR1 gene (Figure 1(a)). Primer sequences and PCR conditions of all SNPs are shown in Table 1. A single-tube multiplex PCR was performed in a $10 \mu \mathrm{L}$ reaction containing $50 \mathrm{ng}$ of genomic DNA, 1x PCR buffer, $200 \mu \mathrm{M}$ dNTPs, and 0.5 U Taq DNA polymerase (Invitrogen). The $\mathrm{MgCl}_{2}$ concentration and the presence or absence of an adjuvant in the PCR reactions were optimized to obtain the maximum yield of multiplex PCR products. In order to enhance the efficiency of allele-specific amplification, the concentration ratios of tetraprimer for each SNP assay were adjusted to produce a similar band intensity of each PCR product after gel electrophoresis. For the rs25731 SNP locus, PCR reactions were performed in a $20 \mu \mathrm{L}$ PCR reaction consisting of $100 \mathrm{ng}$ of genomic DNA, 1x PCR buffer, $200 \mu \mathrm{M}$ dNTPs, $1.5 \mathrm{mM} \mathrm{MgCl}_{2}, 0.25 \mu \mathrm{M}$ of each primer, and $1 \mathrm{U}$ Taq DNA polymerase. The reactions were initially denatured for $5 \mathrm{~min}$ at $95^{\circ} \mathrm{C}$, followed by 35 cycles of $30 \mathrm{sec}$ at $95^{\circ} \mathrm{C}, 30 \mathrm{sec}$ at appropriate annealing temperature, and $30 \mathrm{sec}$ at $72^{\circ} \mathrm{C}$ and a final extension at $72^{\circ} \mathrm{C}$ for $10 \mathrm{~min}$. Then $4 \mu \mathrm{L}$ of the rs 25731 PCR reaction was digested with 4 units of DraI. Direct PCR products or digested PCR products were electrophoresed on $2.5 \%$ agarose gel and stained with ethidium bromide.

2.3. Sequencing Analysis of AGG Interruption Patterns. For accurate AGG interruption patterns, direct sequencing across the CGG repeats region was performed with primer A [1] and primer $571 \mathrm{R}$ [19] in a $50 \mu \mathrm{L}$ reaction volume comprised of $250 \mathrm{ng}$ of genomic DNA, 50.25 mM Tris- $\mathrm{HCl} \mathrm{pH} \mathrm{8.8,}$ 


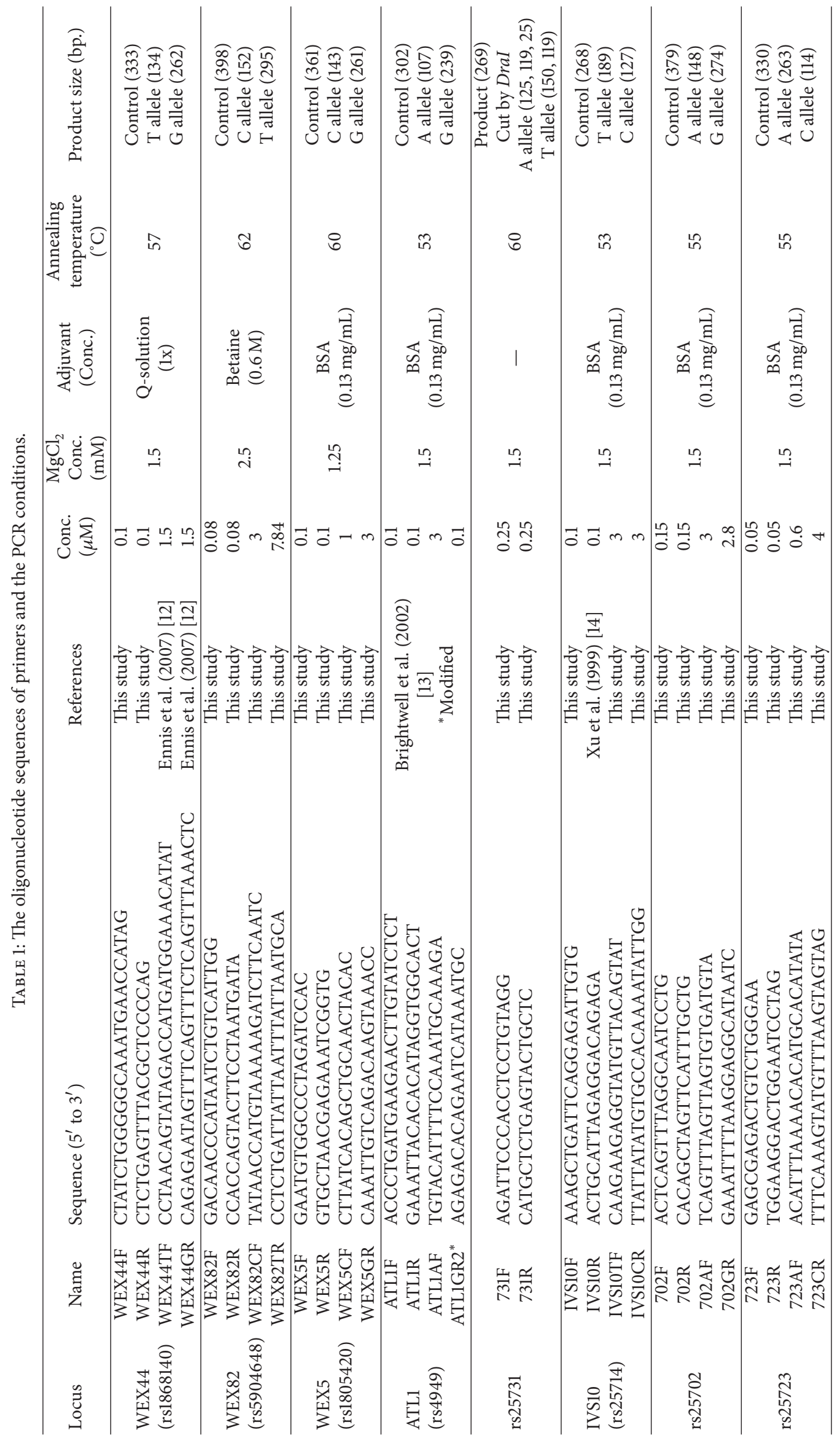


$12.45 \mathrm{mM}\left(\mathrm{NH}_{4}\right)_{2} \mathrm{SO}_{4}, 1 \mathrm{mM} \mathrm{MgCl} 2,200 \mu \mathrm{M}$ dATP, $200 \mu \mathrm{M}$ dCTP, $200 \mu \mathrm{M}$ dTTP, $100 \mu \mathrm{M}$ dGTP, $100 \mu \mathrm{M}$ 7-deaza dGTP, $0.25 \mu \mathrm{M}$ of each primer, $10 \%$ DMSO, $128 \mu \mathrm{g} / \mathrm{mL}$ BSA, and 2.5 units of Immolase DNA polymerase (Bioline). The PCR reactions were initially denatured for $9 \mathrm{~min}$ at $95^{\circ} \mathrm{C}$, followed by 35 cycles of $1 \mathrm{~min}$ at $95^{\circ} \mathrm{C}, 1 \mathrm{~min}$ at $64^{\circ} \mathrm{C}$, and $1 \mathrm{~min}$ at $72^{\circ} \mathrm{C}$ and a final extension at $72^{\circ} \mathrm{C}$ for $10 \mathrm{~min}$. The PCR products were purified by a QIA quick PCR purification kit (Qiagen). Sequencing reactions were carried out in a $10 \mu \mathrm{L}$ reaction consisting of $1 \mathrm{x}$ BigDye terminator v1.1 ready reaction premix and $1.6 \mu \mathrm{M}$ of the internal sequencing primer FXS-SEQF ( $5^{\prime}$-TCTGAGCGGGCGGCGGGCCGA$3^{\prime}$ ) for forward reactions or primer $571 \mathrm{R}$ for reverse reactions. Cycle sequencing conditions were performed in a GeneAmp PCR System 9700 thermal cycler with a temperature profile of $1 \mathrm{~min}$ at $96^{\circ} \mathrm{C}$ followed by 25 cycles of $10 \mathrm{sec}$ at $96^{\circ} \mathrm{C}$ and $4 \mathrm{~min}$ at $60^{\circ} \mathrm{C}$. The sequencing products were purified to remove unincorporated fluorescent dye terminator using a DyeEx 2.0 spin kit (Qiagen). All sequencing pellets were dissolved with $15 \mu \mathrm{L}$ template suppressor reagent and separated by an ABI PRISM 310 genetic analyzer. The AGG interruption patterns were written in abbreviation, for example, 9A9A9, where 9 was (CGG) 9 and A was AGG.

2.4. Data Analysis. The Haploview 4.2 program was used for SNP haplotypes analysis. We used Fisher's exact tests to examine the differences in haplotype frequencies among CGG repeat groups. The significant $P$ value was assigned at 0.05 .

\section{Results}

3.1. Haplotype Analysis. The high linkage disequilibrium found among the 8 SNPs studied is shown in Figure 1(b). Allele frequencies of all SNPs are shown in Table 2. When we analyzed the SNP haplotypes, three major haplotypes, GCGGATAA (Hap A), GCCGTTAA (Hap B), and TTCATCGC (Hap C), were found. The rare haplotypes (Hap D) included 11 different haplotypes with frequencies of less than $5 \%$ each. Hap A was similar to Hap B with 2 allele differences in the SNP loci (rs1805420 and rs25731) whereas Hap A was different from Hap C for all alleles in 8 SNPs.

3.2. Association of SNP Haplotypes and CGG Repeats. We divided the 176 samples into 6 groups based on the common and uncommon CGG repeats from small to large alleles (1928, 29, 30, 31-35, 36, and 37-56) shown in Table 3. Strikingly, we found statistically significant associations between haplotypes and the common CGG repeat groups (Fisher's exact test $<0.001$ ) but no statistical significance was found in other uncommon CGG repeat groups (Fisher's exact test $=0.0955)$. The 29-CGG-repeat group was associated with Hap A (41/55 or 74.5\%), while the 30-CGG-repeat group was associated with Hap C (30/37 or $81.1 \%)$. In contrast, only one chromosome with Hap A and Hap C was observed in each of the 30- and 29-CGG-repeat groups. The 36-CGG-repeat group was associated with Hap B (27/32 or $84.4 \%)$. Hap B was not present in the 30-CGG-repeat group and only a few occurrences were noted in the 29-CGG-repeat group (5.5\%).
TABLE 2: The allele frequencies of the 8 SNPs studied.

\begin{tabular}{lcc}
\hline SNP & Major allele (\%) & Minor allele (\%) \\
\hline WEX44 (rs1868140) & $\mathrm{G}(65.9)$ & $\mathrm{T}(34.1)$ \\
WEX82 (rs5904648) & $\mathrm{C}(65.3)$ & $\mathrm{T}(34.7)$ \\
WEX5 (rs1805420) & $\mathrm{C}(57.4)$ & $\mathrm{G}(42.6)$ \\
ATL1 (rs4949) & $\mathrm{G}(67.0)$ & $\mathrm{A}(33.0)$ \\
rs25731 & $\mathrm{T}(58.0)$ & $\mathrm{A}(42.0)$ \\
IVS10 (rs25714) & $\mathrm{T}(64.2)$ & $\mathrm{C}(35.8)$ \\
rs25702 & $\mathrm{A}(64.2)$ & $\mathrm{G}(35.8)$ \\
rs25723 & $\mathrm{A}(64.8)$ & $\mathrm{C}(35.2)$ \\
\hline
\end{tabular}

The large CGG repeat (37-56) group was related to Hap A or Hap B (12/15 or $80 \%)$, while the 19-28- and 31-35-CGG-repeat groups had $44.4 \%(8 / 18)$ and $31.6 \%(6 / 19)$ of Hap A and Hap $\mathrm{B}$, respectively.

3.3. Association of SNP Haplotypes and AGG Interruption Patterns. We randomly selected $95 \mathrm{X}$ chromosomes from 176 samples (54\%) for DNA sequencing, including uncommon and common alleles. The results revealed variety in both numbers of AGG and AGG interruption patterns in the CGG repeats of the FMR1 gene (Figure 2). Most normal alleles had 2 AGG interruptions (48/95 or 50.5\%). Alleles with a single or 3 AGG interruptions had the same frequencies of 20\% (19/95). The no AGG and 4 AGG interruptions had frequencies of $4.2 \%$ (4/95) and 5.3\% (5/95), respectively. The no AGG interruption was found in either low CGG repeats (21) or high CGG repeats (43 and 56) while the 4-AGG interruption was found in only high CGG repeats (43 and 45). The 3-AGG and 4-AGG interruptions were exclusively found in the Hap A and Hap B groups. However, no AGG and 2-AGG interruptions were found in all haplotypes. We also observed an allele possessing a $5^{\prime}$ tract with 20 CGG repeats (20A9). The 29 -CGG-repeat group with Hap A had an AGG configuration of 9A9A9 (10/17). The 30-CGG-repeat group with Hap C had an AGG configuration of 10A9A9 (16/18). The 36 CGG repeats with Hap B had an AGG configuration of 9A9A6A9 (13/18). This (CGG)6AGG pattern seemed specific to chromosomes with Hap B (i.e., 10A $\underline{6 A} 9$ in 27 CGG repeats, 12A6A9 in 29 CGG repeats, 9A9A6 $\underline{\mathrm{A} 9}$ in 36 CGG repeats, 9A9A6A6A9 in 43 CGG repeats, and 9A9A6A8A9 in $45 \mathrm{CGG}$ repeats). Only one chromosome with Hap B had the 9A23 pattern (33 CGG repeats) from 23 chromosomes with Hap B studied. Likewise, we observed that the 9A and 10A patterns at $5^{\prime}$ of the CGG repeats tract were related to Hap A and Hap $\mathrm{C}$, respectively.

\section{Discussion}

The haplotype analysis using 8 SNPs in the present study provided more information than in previous studies $[9,17]$ which could not distinguish haplotypes with 29 CGG repeats from those with 36 CGG repeats (the third common allele exclusively found in Asians). Most chromosomes with 29 
TABLE 3: SNP haplotypes frequencies in different CGG repeat groups.

\begin{tabular}{|c|c|c|c|c|c|c|c|}
\hline \multirow[b]{2}{*}{ Haplotype } & \multicolumn{7}{|c|}{ Frequencies of the CGG groups (number) } \\
\hline & $\begin{array}{c}19-28 \mathrm{CGG}^{* *} \\
(18)\end{array}$ & $\begin{array}{c}29 \mathrm{CGG}^{*} \\
(55)\end{array}$ & $\begin{array}{c}30 \mathrm{CGG}^{*} \\
(37)\end{array}$ & $\begin{array}{c}31-35 \mathrm{CGG}^{* *} \\
(19)\end{array}$ & $\begin{array}{c}36 \mathrm{CGG}^{*} \\
(32)\end{array}$ & $\begin{array}{c}37-56 \mathrm{CGG}^{* *} \\
(15)\end{array}$ & $\begin{array}{c}\text { Total } \\
\text { number } \\
(176)\end{array}$ \\
\hline $\begin{array}{l}\text { GCGGATAA } \\
(\text { Hap A) }\end{array}$ & $\begin{array}{l}0.278 \\
(5)\end{array}$ & $\begin{array}{c}0.745 \\
(41)\end{array}$ & $\begin{array}{l}0.027 \\
(1)\end{array}$ & $\begin{array}{c}0.263 \\
(5)\end{array}$ & $\begin{array}{c}0.156 \\
(5)\end{array}$ & $\begin{array}{l}0.467 \\
(7)\end{array}$ & $\begin{array}{c}0.364 \\
(64)\end{array}$ \\
\hline $\begin{array}{l}\text { GCCGTTAA } \\
(\text { Hap B) }\end{array}$ & $\begin{array}{c}0.167 \\
(3)\end{array}$ & $\begin{array}{c}0.055 \\
(3)\end{array}$ & 0 & $\begin{array}{l}0.053 \\
(1)\end{array}$ & $\begin{array}{c}0.844 \\
(27)\end{array}$ & $\begin{array}{c}0.333 \\
(5)\end{array}$ & $\begin{array}{c}0.222 \\
(39)\end{array}$ \\
\hline $\begin{array}{l}\text { TTCATCGC } \\
\text { (Hap C) }\end{array}$ & $\begin{array}{c}0.333 \\
(6)\end{array}$ & $\begin{array}{l}0.018 \\
(1)\end{array}$ & $\begin{array}{r}0.811 \\
(30)\end{array}$ & $\begin{array}{c}0.526 \\
(10)\end{array}$ & 0 & $\begin{array}{l}0.200 \\
(3)\end{array}$ & $\begin{array}{c}0.284 \\
(50)\end{array}$ \\
\hline $\begin{array}{l}\text { Rare haplotypes } \\
\text { (Hap D) }\end{array}$ & $\begin{array}{l}0.222 \\
(4)\end{array}$ & $\begin{array}{c}0.182 \\
(10)\end{array}$ & $\begin{array}{c}0.162 \\
(6)\end{array}$ & $\begin{array}{c}0.158 \\
(3)\end{array}$ & 0 & 0 & $\begin{array}{c}0.130 \\
(23)\end{array}$ \\
\hline
\end{tabular}

Comparison based on CGG repeats groups.

${ }^{*}$ Common CGG repeat groups (29, 30, and 36; Fisher's exact test; $P$ value $<0.001$; statistical significance).

${ }^{* *}$ Uncommon CGG repeat groups (19-28, 31-35, and 37-56; Fisher's exact test; $P$ value $=0.0955$; no statistical significance).

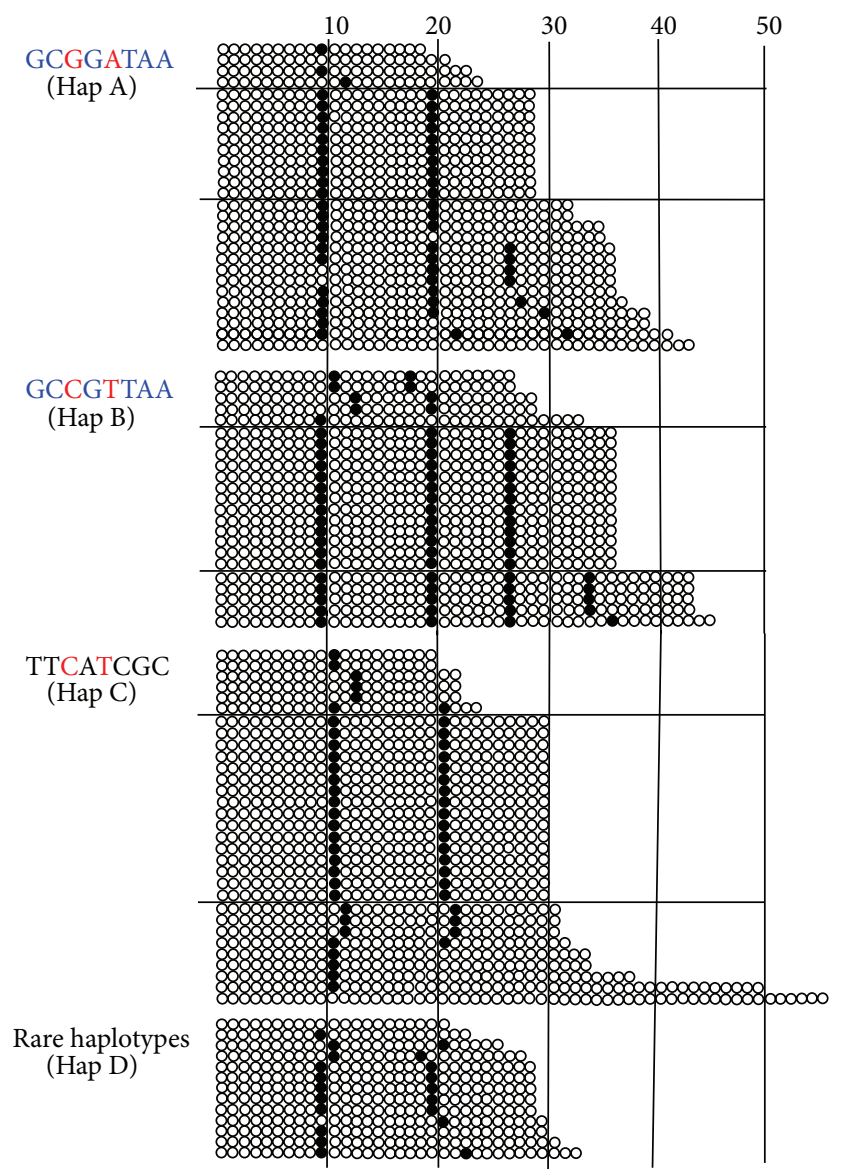

FIGURE 2: AGG interruption patterns of $95 \mathrm{X}$ chromosomes. The CGG repeats are classified in haplotype groups. The AGG interruption patterns are shown from the $5^{\prime}$ to the $3^{\prime}$ ends of the CGG repeat tracts. A white circle represents a CGG and a black circle represents an AGG. The numbers of CGG repeats are indicated as numbers on top of the vertical lines $(10,20,30,40$, and 50$)$.

and 36 CGG repeats in Thai, Chinese, and Malay populations have G-T of the ATL1-IVS10 haplotype while the A-C haplotype was linked to chromosomes with 30 CGG repeats in Thai, Malay, Chinese, and Indian populations [9, 17]. Table 2 shows that the 29 and 36 CGG repeat groups had different haplotypes from two SNPs (rs1805420, rs25731).

Analysis of haplotypes using 8 SNPs in our study showed significant associations between haplotypes and the common CGG repeats $(29,30$, and 36). The 29-CGG-repeat group was associated with haplotype GCGGATAA (Hap A), the 30-CGG-repeat group was associated with haplotype TTCATCGC (Hap C), and the 36-CGG-repeat group was associated with haplotype GCCGTTAA (Hap B). The uncommon CGG repeats of the $19-28,31-35$, and $37-56$ groups were not associated with any haplotype and had similar distributions of haplotypes. These findings suggest that uncommon CGG repeats randomly occur in all three common and rare haplotypes.

Most of chromosomes with 36 CGG repeats and Hap $B$ had an AGG configuration of 9 A9A6A9 that might be derived from chromosomes with 29 CGG repeats and Hap A (9A9A9) by 6A insertion [5]. This formation was also found in chromosomes with 43 CGG repeats and Hap B (9A9A6A6A9), which might be derived from chromosomes with 36 CGG repeats and Hap B by 6A insertion (Figure 3 ). However, a few Hap B-chromosomes with 27 and 29 CGG repeats had AGG configurations of $10 \mathrm{~A} 6 \mathrm{~A} 9$ and $12 \mathrm{~A} 6 \mathrm{~A} 9$ that might be derived from 20 (10A9) and 22 (12A9) CGG repeats of chromosomes with Hap $\mathrm{C}$ by insertion of $6 \mathrm{~A}$ pattern (Figure 3).

Hap A and Hap C had different alleles in all SNPs. This suggests that Hap A and Hap C may have different evolutionary pathways. However, Hap A and Hap B are likely evolutionarily derived since they had similar SNP haplotypes (Table 3) and both haplotypes carried 9A pattern at $5^{\prime}$ of the CGG repeats tract (Figures 2 and 3 ). The evolution of CGG repeats is likely from primitive small to large CGG repeats. An evolutionary study of the CGG repeats of the $F M R 1$ gene showed that most nonprimate mammals have a small number of uninterrupted CGG repeats with a mean of $\sim 8$ repeats, while the repeats of primates are larger with a mean of $\sim 20$ repeats and more highly specific interruptions [20]. Therefore, we hypothesize that there may be two distinct 


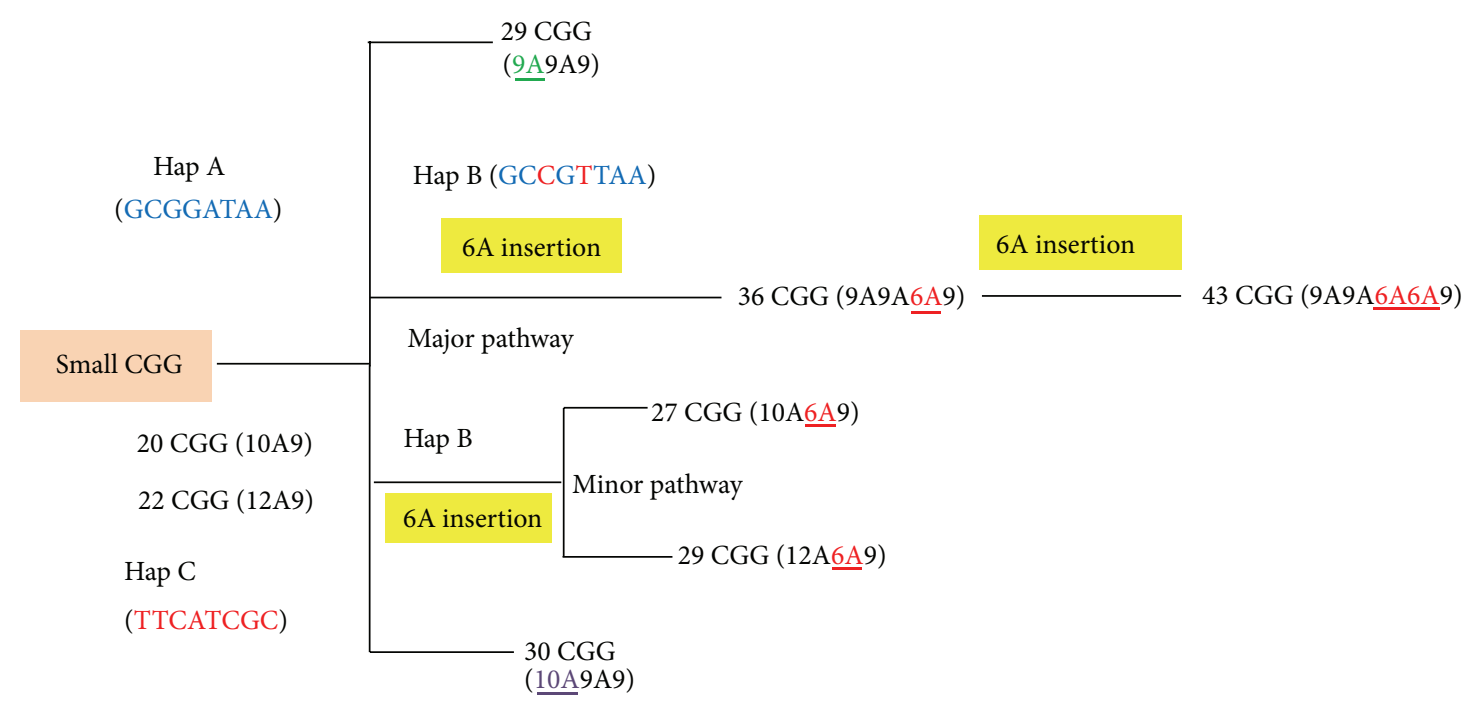

FIGURE 3: Simplified evolutionary pathways of the hypothesis. Chromosomes with 29 and 30 CGG repeats may have different evolutionary pathways since they had different haplotypes and AGG interruption patterns. The 6A pattern was linked to Hap B possibly derived from chromosomes with Hap A (major pathway) or Hap C (minor pathway).

pathways in our findings. First, chromosomes with 29 and 30 CGG repeats may independently arise from Hap A and Hap C by gradual replication slippage or recombination via the smaller alleles [20] and were stable by the 9A9A9 and 10A9A9 patterns, respectively $[11,21]$. Second, the 6 A pattern was linked to chromosomes with Hap B possibly derived from chromosomes with Hap A (major pathway) or Hap C (minor pathway). Simplified pathways of the hypothesis are shown in Figure 3. In addition, perhaps the 6A pattern enhances the stability of CGG repeat tracts $[22,23]$. Thus, chromosomes with 36 CGG repeats linked to the 6A pattern have become the third most common allele in only Asian populations. It is also relevant to note that, to date, the $6 \mathrm{~A}$ pattern has been exclusively found in Asians [5-11]. A study based on an Eskimo population indicated that the $6 \mathrm{~A}$ pattern has been stably conserved for 15,000-30,000 years, since this group migrated from Asia to North America [7].

It has been proposed that AGG interruptions play a crucial role in maintaining the stability of the CGG repeats since premutation alleles often contain only one AGG or no AGG interruptions [3, 4, 24-26]. Haplotypes analysis using microsatellites near the FMR1 gene (DXS548-FRAXAC1FRAXAC2) found that specific haplotypes were associated with the loss of AGG interruptions of the CGG repeats in Caucasians [27] and Jewish Tunisians [28]. In contrast, the findings in African Americans using those three microsatellites and the SNP, ATL1 did not show a haplotype association with CGG repeats instability [29]. Also, our findings in this study support earlier studies where the SNP haplotype association between nearby SNPs and AGG interruption patterns in CGG repeats of the FMR1 gene likely reflects linkage disequilibrium in each population $[9,17,30]$. Therefore, it is difficult to determine if an associated haplotype is a real factor for CGG repeats instability or a linkage disequilibrium in a specific population [31].

\section{Conclusion}

Our study showed new evidence that the specific haplotype (Hap B) was strongly linked to the 6A pattern in Thai subjects since almost all chromosomes with Hap B had at least one $6 \mathrm{~A}$ configuration, regardless of $\mathrm{CGG}$ repeats (i.e., 10A6A9, 12A6A9, 9A9A6A6A9, and 9A9A9A6A8A9). The $6 \mathrm{~A}$ pattern and Hap $\mathrm{B}$ may have originally occurred in the ancestors of Asian populations. However, we could not completely exclude that the findings may be by chance or sample selection bias. Further studies of SNP haplotypes and AGG interruption patterns in other Asian populations would be warranted, to confirm and expand on our findings.

\section{Conflict of Interests}

The authors declare that they have no conflict of interests.

\section{Acknowledgments}

The authors would like to thank Ms. Charunee Maharat, Ms. Supaporn Yangngam, and Ms. Oradawan Plong-On for technical assistance. This work was supported by the Graduate School, Prince of Songkla University (EC. 48/364010), and was partly supported by the National Center for Genetic Engineering and Biotechnology (BIOTEC) Grant no. BT-B-01-MG-18-4814.

\section{References}

[1] Y.-H. Fu, D. P. A. Kuhl, A. Pizzuti et al., "Variation of the CGG repeat at the fragile $\mathrm{X}$ site results in genetic instability: resolution of the sherman paradox," Cell, vol. 67, no. 6, pp. 10471058, 1991.

[2] M. Pieretti, F. Zhang, Y.-H. Fu et al., "Absence of expression of the FMR-1 gene in fragile X syndrome," Cell, vol. 66, no. 4, pp. 817-822, 1991. 
[3] E. E. Eichler, J. J. A. Holden, B. W. Popovich et al., "Length of uninterrupted CGG repeats determines instability in the FMR1 gene," Nature Genetics, vol. 8, no. 1, pp. 88-94, 1994.

[4] C. B. Kunst and S. T. Warren, "Cryptic and polar variation of the fragile $\mathrm{X}$ repeat could result in predisposing normal alleles," Cell, vol. 77, no. 6, pp. 853-861, 1994.

[5] S.-H. Chen, J. M. Schoof, N. E. Buroker, and C. R. Scott, "The identification of a (CGG)6AGG insertion within the CGG repeat of the FMR1 gene in Asians," Human Genetics, vol. 99, no. 6, pp. 793-795, 1997.

[6] M. C. Hirst, T. Arinami, and C. D. Laird, "Sequence analysis of long FMR1 arrays in the Japanese population: insights into the generation of long (CGG) n tracts," Human Genetics, vol. 101, no. 2, pp. 214-218, 1997.

[7] L. A. Larsen, J. S. M. Armstrong, K. Gronskov et al., "Analysis of FMR1(CGG) $)_{\mathrm{n}}$ alleles and FRAXA microsatellite haplotypes in the population of Greenland: implications for the population of the New World from Asia," European Journal of Human Genetics, vol. 7, no. 7, pp. 771-777, 1999.

[8] S. M. H. Faradz, J. Leggo, A. Murray, P. R. L. Lam-Po-Tang, M. F. Buckley, and J. J. A. Holden, "Distribution of FMR1 and FMR2 alleles in Javanese individuals with developmental disability and confirmation of a specific AGG-interruption pattern in Asian populations," Annals of Human Genetics, vol. 65, no. 2, pp. 127135, 2001.

[9] Y. Zhou, K. Tang, H.-Y. Law, I. S. L. Ng, C. G. L. Lee, and S. S. Chong, "FMR1 CGG repeat patterns and flanking haplotypes in three Asian populations and their relationship with repeat instability," Annals of Human Genetics, vol. 70, no. 6, pp. 784796, 2006.

[10] H.-H. Chiu, Y.-T. Tseng, H.-P. Hsiao, and H.-H. Hsiao, “The AGG interruption pattern within the CGG repeat of the FMR1 gene among Taiwanese population," Journal of Genetics, vol. 87, no. 3, pp. 275-277, 2008.

[11] C. M. Yrigollen, S. Sweha, B. Durbin-Johnson et al., "Distribution of AGG interruption patterns within nine world populations," Intractable \& Rare Diseases Research, vol. 3, no. 4, pp. 153-161, 2014.

[12] S. Ennis, A. Murray, G. Brightwell, N. E. Morton, and P. A. Jacobs, "Closely linked cis-acting modifier of expansion of the CGG repeat in high risk FMR1 haplotypes," Human Mutation, vol. 28, no. 12, pp. 1216-1224, 2007.

[13] G. Brightwell, R. Wycherley, and A. Waghorn, "SNP genotyping using a simple and rapid single-tube modification of ARMS illustrated by analysis of 6 SNPs in a population of males with FRAXA repeat expansions," Molecular and Cellular Probes, vol. 16, no. 4, pp. 297-305, 2002.

[14] B. Xu, J. M. Schoof, N. E. Buroker, C. R. Scott, and S. H. Chen, "High frequency of the FMR1 IVS10+14C/T polymorphism in Asians, and its association with the fragile $\mathrm{X}$ syndrome in Caucasians," The American Journal of Human Genetics, vol. 65, supplement, abstract 2282, 1999.

[15] P. Limprasert, N. Ruangdaraganon, T. Sura, P. Vasiknanonte, and U. Jinorose, "Molecular screening for fragile $\mathrm{X}$ syndrome in Thailand," The Southeast Asian Journal of Tropical Medicine and Public Health, vol. 30, supplement 2, pp. 114-118, 1999.

[16] C. Charalsawadi, T. Sripo, and P. Limprasert, "Multiplex methylation specific PCR analysis of fragile X syndrome: experience in Songklanagarind Hospital," Journal of the Medical Association of Thailand, vol. 88, no. 8, pp. 1057-1061, 2005.
[17] P. Limprasert, V. Saechan, N. Ruangdaraganon et al., "Haplotype analysis at the FRAXA locus in Thai subjects," American Journal of Medical Genetics, vol. 98, no. 3, pp. 224-229, 2001.

[18] G. Brightwell, R. Wycherley, G. Potts, and A. Waghorn, "A highdensity SNP map for the FRAX region of the X chromosome," Journal of Human Genetics, vol. 47, no. 11, pp. 567-575, 2002.

[19] S. S. Chong, E. E. Eichler, D. L. Nelson, and M. R. Hughes, "Robust amplification and ethidium-visible detection of the fragile X syndrome CGG repeat using Pfu polymerase," American Journal of Medical Genetics, vol. 51, no. 4, pp. 522-526, 1994.

[20] E. E. Eichler, C. B. Kunst, K. A. Lugenbeel et al., "Evolution of the cryptic FMR1 CGG repeat," Nature Genetics, vol. 11, no. 3, pp. 301-308, 1995.

[21] G. J. Latham, J. Coppinger, A. G. Hadd, and S. L. Nolin, "The role of AGG interruptions in fragile $\mathrm{X}$ repeat expansions: a twentyyear perspective," Frontiers in Genetics, vol. 5, no. 7, article 244, Article ID Article 244, 2014.

[22] P. Weisman-Shomer, E. Cohen, and M. Fry, "Interruption of the fragile $\mathrm{X}$ syndrome expanded sequence $\mathrm{d}(\mathrm{CGG})_{n}$ by interspersed $\mathrm{d}(\mathrm{AGG})$ trinucleotides diminishes the formation and stability of $\mathrm{d}(\mathrm{CGG})_{n}$ tetrahelical structures," Nucleic Acids Research, vol. 28, no. 7, pp. 1535-1541, 2000.

[23] C. B. Volle and S. Delaney, "AGG/CCT interruptions affect nucleosome formation and positioning of healthy-length CGG/CCG triplet repeats," BMC Biochemistry, vol. 14, no. 1, article 33, 2013.

[24] M. C. Hirst, P. K. Grewal, and K. E. Davies, "Precursor arrays for triplet repeat expansion at the fragile X locus," Human Molecular Genetics, vol. 3, no. 9, pp. 1553-1560, 1994.

[25] K. Snow, D. J. Tester, K. E. Kruckeberg, D. J. Schaid, and S. $\mathrm{N}$. Thibodeau, "Sequence analysis of the fragile X trinucleotide repeat: implications for the origin of the fragile X mutation," Human Molecular Genetics, vol. 3, no. 9, pp. 1543-1551, 1994.

[26] N. Zhong, W. Yang, C. Dobkin, and W. T. Brown, "Fragile X gene instability: anchoring AGGs and linked microsatellites," The American Journal of Human Genetics, vol. 57, no. 2, pp. 351361, 1995.

[27] E. E. Eichler, J. N. Macpherson, A. Murray, P. A. Jacobs, A. Chakravarti, and D. L. Nelson, "Haplotype and interspersion analysis of the FMR1 CGG repeat identifies two different mutational pathways for the origin of the fragile X syndrome," Human Molecular Genetics, vol. 5, no. 3, pp. 319-330, 1996.

[28] T. C. Falik-Zaccai, E. Shachak, M. Yalon et al., "Predisposition to the fragile $\mathrm{X}$ syndrome in Jews of Tunisian descent is due to the absence of AGG interruptions on a rare Mediterranean haplotype," The American Journal of Human Genetics, vol. 60, no. 1, pp. 103-112, 1997.

[29] D. C. Crawford, C. E. Schwartz, K. L. Meadows et al., "Survey of the fragile X syndrome CGG repeat and the short-tandemrepeat and single-nucleotide-polymorphism haplotypes in an African American population," American Journal of Human Genetics, vol. 66, no. 2, pp. 480-493, 2000.

[30] M. Barasoain, G. Barrenetxea, E. Ortiz-Lastra et al., "Single nucleotide polymorphism and FMR1 CGG repeat instability in two Basque valleys," Annals of Human Genetics, vol. 76, no. 2, pp. 110-120, 2012.

[31] S. Ennis, A. Murray, and N. E. Morton, "Haplotypic determinants of instability in the FRAX region: concatenated mutation or founder effect?" Human Mutation, vol. 18, no. 1, pp. 61-69, 2001. 

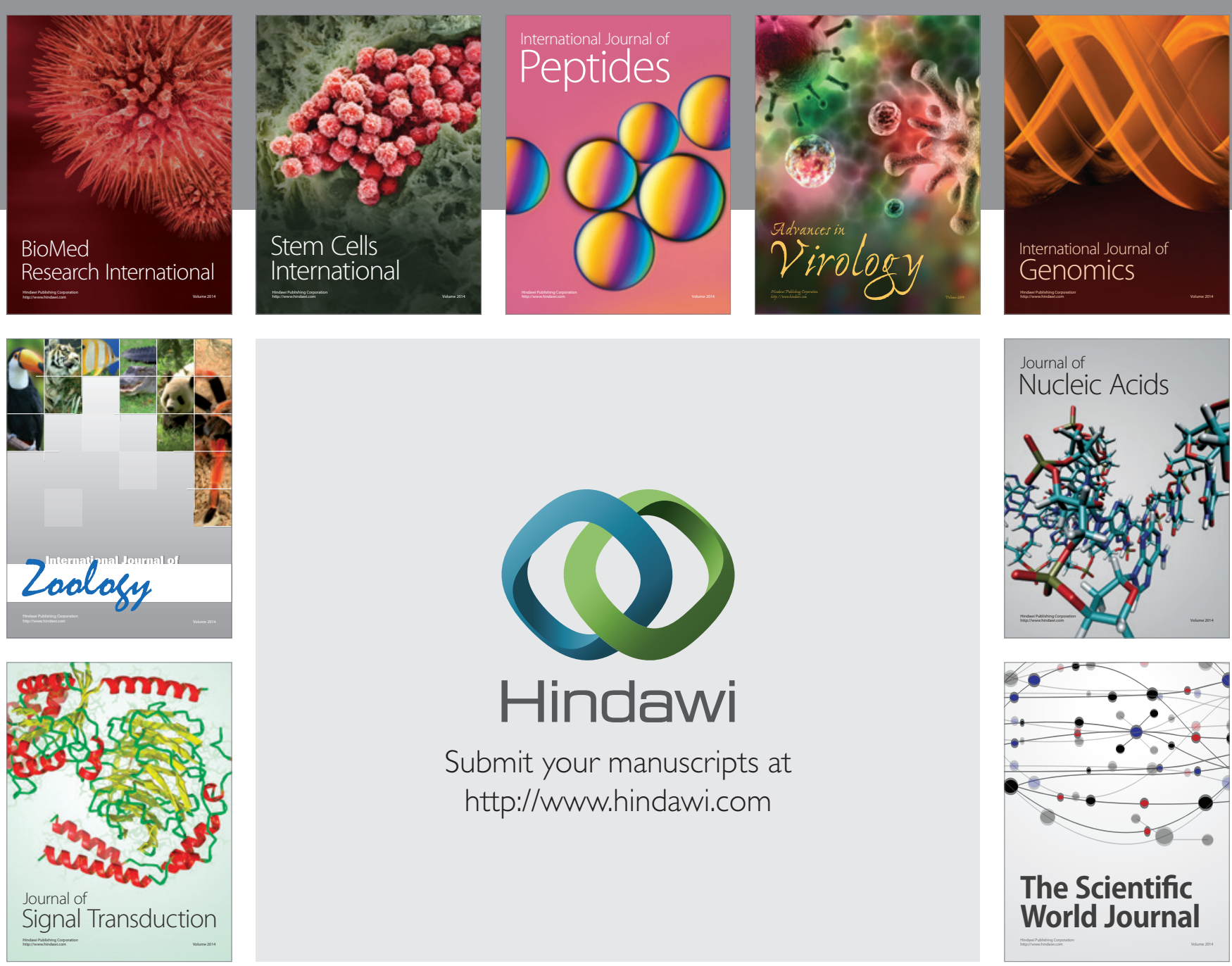

Submit your manuscripts at

http://www.hindawi.com
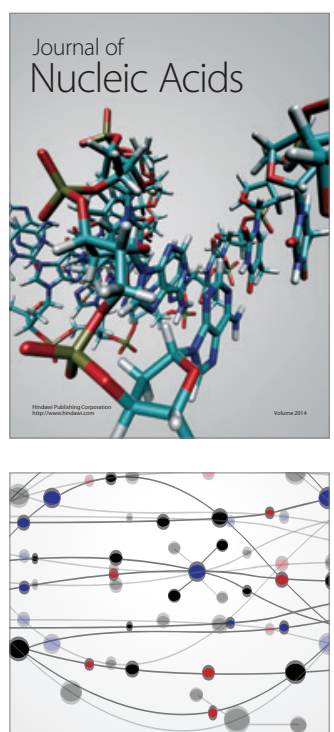

The Scientific World Journal
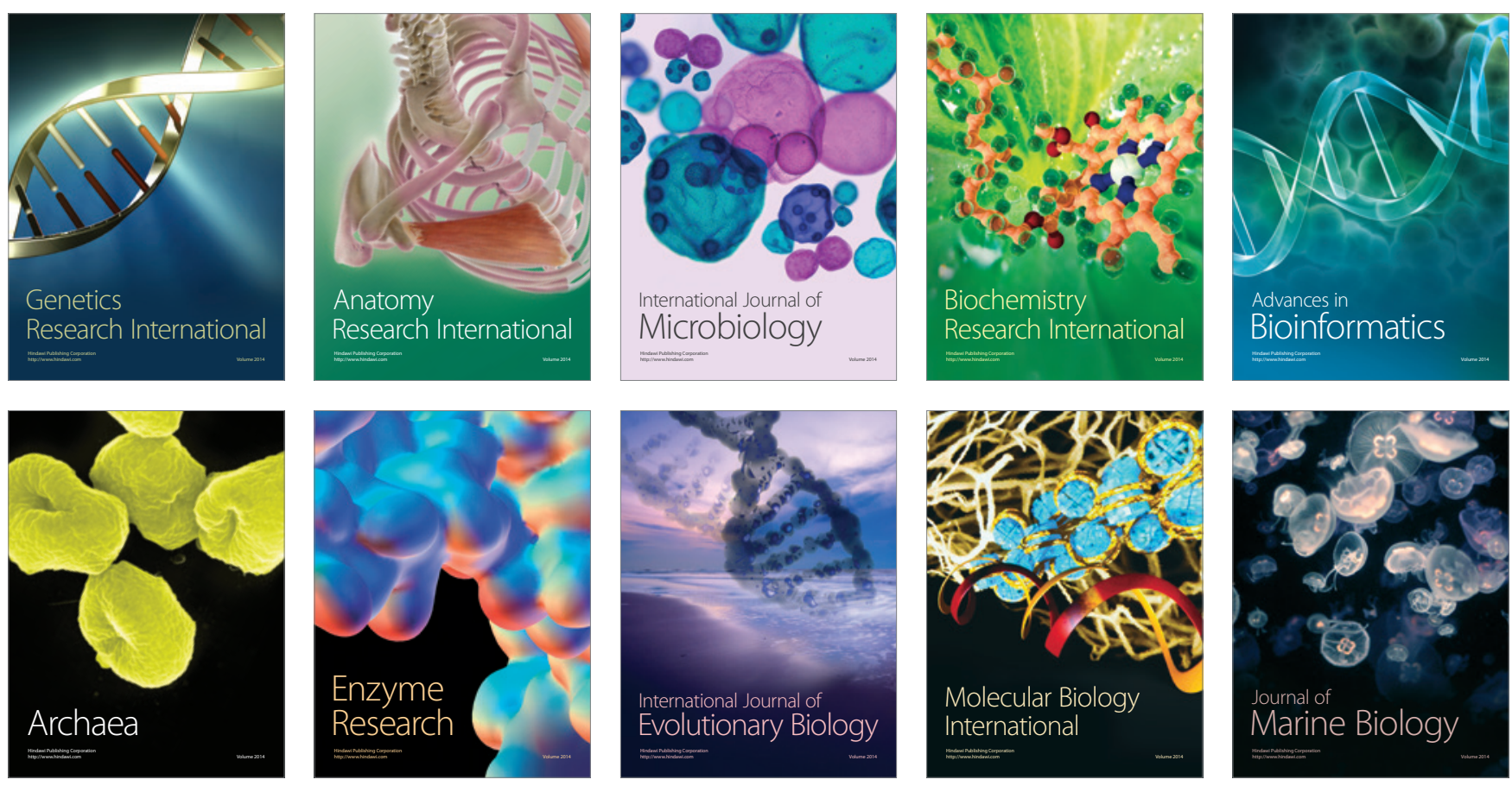